\title{
Future Prospects
}

\author{
Rajeev K. Varshney, Rachit K. Saxena \\ and Scott A. Jackson
}

\begin{abstract}
Pigeonpea with limited genetic diversity in the cultivated gene pool, long crop cycle, almost negligible public funding support to research as compared to other food crops remained an orphan crop. However, the development of extensive genetic stocks and genomics resources in recent years has made significant advances in pigeonpea research. Although genome sequence, genetic maps and a large set of markers allowed genome-wide identification of marker-traits associations and their deployment in breeding programs, there is a need for concerted community efforts to accelerate genetic gains in the crop breeding programs. This chapter proposes the use of a number of approaches that may be targeted by pigeonopea research community so that superior varieties or hybrids can be developed and disseminated to farmers in relatively short time. This will help to enhance the income of farmers as well as contributing to the food, nutritional and environmental sustainability in developing countries.
\end{abstract}

R.K. Varshney $(\bowtie) \cdot$ R.K. Saxena International Crops Research Institute for the Semi-Arid Tropics (ICRISAT), Patancheru 502324, India

e-mail: r.k.varshney@cgiar.org

\section{S.A. Jackson}

The University of Georgia, College of Agricultural and Environmental Sciences, Athens, GA 30602, USA

\subsection{Introduction}

More than 100 pigeonpea varieties and three hybrids (ICPH 2671, ICPH 2740 and ICPH 3762) have been released for cultivation (Singh et al. 2005; Saxena 2015), and thousands of germplasm accessions are present in the genebanks (Upadhyaya et al. 2006). However, the actual yield potential of pigeonpea has not been realized in farmers' fields (Mula and Saxena 2010). As discussed in many earlier chapters in this book, the yield levels remain stagnated during last seven decades. Moreover, the poor understanding of 
genetics of many complex traits and limited concerted efforts in pigeonpea research and development has also been a contributing factor to develop the varieties and hybrids in relatively long time and with limited advantages over existing varieties/hybrids. Although hybrid technology has shown promise in elevating the yield levels in pigeonpea, its adoption has been limited to confined regions (Saxena et al. 2013). Very recently, new genomics approaches such as structural and functional genomics have started to enhance our understanding of genetic architecture of different traits in pigeonpea. Further, the advances in sequencing technologies have opened new opportunities for using a number of strategies to understand the complex traits and address the production constraints by developing new cultivars at a rapid pace. Therefore, in this chapter, we are highlighting futuristic approaches that can be used to enhance the genetic gains in pigeonpea breeding programs.

\subsection{Genome Sequencing and Re-sequencing}

Limited genetic diversity in crop species like pigeonpea poses threat to the crop to be more vulnerable to diseases, insect pests and climate change. Therefore, it is highly essential to continuously characterize and introduce novel genetic variations in crop breeding programs. This can be achieved by introducing mutants, landraces and wild species accessions related to the cultivated crop in breeding programs. However, linkage drag associated with favourable alleles in landraces and wild species accessions hindered their effective use in crop improvement (Sharma et al. 2013). The availability of next generation sequencing (NGS) and draft genome sequence in pigeonpea provides unique opportunities for exploring nucleotide-level diversity in cultivated, landraces and wild species accessions and its relationship to phenotypic diversity (Varshney et al. 2012). Re-sequencing of germplasm accessions will provide a better understanding of existing genetic diversity, associating gene(s) with phenotypes and exploiting natural genetic diversity to develop superior genotypes (Varshney et al. 2017). Few recent efforts as mentioned in the book chapters of re-sequencing pigeonpea reference set, hybrid parental lines and parental lines of mapping populations are underway. However, these efforts need to be enhanced exponentially and probably the entire germplasm collections stored in different genebanks should be sequenced. Ideally, we would like to see de novo genome assembly for each of the available Cajanus species and then re-sequencing data for all accessions. Further to use this information effectively, it is also important to have extensive phenotypic data on these collections so that appropriate marker-trait associations can be established.

\subsection{Trait Mapping}

We propose to undertake trait mapping in pigeonpea as mentioned in the following sections:

\section{i. Prioritization of traits}

In order to enhance crop productivity, pigeonpea research community is always concerned for multiple traits related to yield and quality. Besides these traits, research is also focused on biotic and abiotic stresses to provide stability. It is important to prioritize traits as per the availability of human and financial resources in a given breeding program. Keeping this aspect in consideration, we have grouped target traits into three categories (Table 10.1). Category (Cat) 1 traits include immediate (5 years) need traits, Cat 2 traits are long-term (10 years) needs traits and Cat 3 are important traits but difficult to breed ( $>10$ years). Therefore, high priority in implementation should be given to Cat 1 and 2 traits. For Cat 3 traits, consortium mode approach should be followed by bringing advanced research institutes and universities together.

ii. Rapid detection of markers associated with traits 
Table 10.1 List of the traits on the basis of Cat 1 immediate (5 years) need, Cat 2 long-term (10 years) needs and Cat 3 important but difficult to breed ( $>10$ years)

\begin{tabular}{|c|c|c|c|}
\hline Trait & Immediate attention (Cat 1) & Long-term attention (Cat 2) & Difficult, but important (Cat 3) \\
\hline \multirow[t]{9}{*}{ Early maturity group } & Super early ${ }^{\mathrm{a}}$ & Pod borer ${ }^{c}$ & Photo-insensitivity $^{\mathrm{a}}$ \\
\hline & Large seed $^{\mathrm{a}}$ & Phytophthora $^{\mathrm{d}}$ & Races of phytophthora $^{\mathrm{d}}$ \\
\hline & High yield $^{\mathrm{a}}$ & Water-logging $^{\mathrm{d}}$ & \\
\hline & Indeterminate $^{\mathrm{b}}$ & & \\
\hline & Flowering time $^{\mathrm{a}}$ & & \\
\hline & Wide adaptation $^{\mathrm{a}}$ & & \\
\hline & Stable fertility restorers ${ }^{\mathrm{b}}$ & & \\
\hline & Primary branches ${ }^{\mathrm{a}}$ & & \\
\hline & Cleisto flower ${ }^{\mathrm{a}}$ & & \\
\hline \multirow[t]{9}{*}{ Medium/late maturity group } & Fusarium wilt resistance $^{b}$ & Races of fusarium wilt ${ }^{\mathrm{d}}$ & Photo-insensitivity $^{\mathrm{a}}$ \\
\hline & Sterility mosaic resistance ${ }^{b}$ & Races of sterility mosaic ${ }^{\mathrm{d}}$ & Drought tolerance $^{\mathrm{a}}$ \\
\hline & High yield $^{\mathrm{a}}$ & Phytophthora $^{\mathrm{d}}$ & Races of phytophthora $^{\mathrm{d}}$ \\
\hline & Cleisto flower ${ }^{a}$ & Rapid growth $^{\mathrm{d}}$ & High protein ${ }^{\mathrm{a}}$ \\
\hline & Flowering time $^{\mathrm{a}}$ & Pod borer ${ }^{\mathrm{c}}$ & \\
\hline & Hybridity test ${ }^{\mathrm{b}}$ & New $\mathrm{CMS}^{\mathrm{a}}$ & \\
\hline & Diverse fertility restorers ${ }^{a}$ & & \\
\hline & $\begin{array}{l}\text { Primary/secondary } \\
\text { branches }^{\text {a }}\end{array}$ & & \\
\hline & Obcordate leaf shape $^{a}$ & & \\
\hline
\end{tabular}

To improve pigeonpea lines for "must have traits" as mentioned above through genomics-assisted breeding approaches, identification of traits-associated markers/genomic regions/quantitative trait loci (QTLs) or candidate genes are prerequisite. Once a marker (or candidate gene) associated with target traits is identified and validated; marker-assisted selection (MAS), marker-assisted backcrossing (MABC) or early generation screening (EGS) can be deployed for precise and rapid development of improved cultivars. Traditional QTL mapping approach involves identification of parental polymorphisms and genotyping the populations with polymorphic markers in time-consuming and resource intensive manner (Abe et al. 2012). Another common trait mapping approach is bulked segregant analysis (BSA) where marker screening on the extreme bulks and parents provides trait-associated markers (see Semagn et al. 2010). With the advantage of NGS technologies and draft genome sequence, rapid trait mapping has been performed for sterility mosaic disease (SMD) and fusarium wilt (FW) (Singh et al. 2015, 2017). These approaches depend on extreme bulks and NGS to even provide markers for qualitative and quantitative traits. We anticipate in future, heavy use of NGS-based BSA approaches for rapid and accurate trait mapping.

iii. High-resolution mapping

Other than bi-parental mapping populations, multi-parents mapping populations such as multi-parents advanced generation inter-cross (MAGIC) and nested association 
mapping (NAM) populations are being developed in pigeonpea for high-resolution mapping at ICRISAT. These family-based populations can be used for precise marker trait association following either individual or combination of genome-wide association studies and QTL mapping. MAGIC population in particular is useful for gene-trait association at higher resolution (Huang et al. 2012). On the other hand, NAM has advantage in identifying QTLs governing complex traits with higher phenotypic variation (McMullen et al. 2009). The selection of parental lines in developing MAGIC and NAM populations, however, plays an important role. RILs developed after this multi-dimensional crossing will have genetic architecture from a number of elite cultivars (crossing parents) and provides opportunity to evaluate them for must have traits. In summary, this multi-parental populations-based mapping approach will provide accurate means of tagging traits as well line with enhanced genetic diversity (in the case of MAGIC). In our opinion, efforts should also be directed towards utilization of the genetic variations and useful traits existing in many wild relative species of pigeonpea. In this direction, few introgression lines (ILs) have been developed at ICRISAT. However, there is still a scope to move towards backcross inbred lines (BILs), chromosome segment substitution lines (CSSLs), stepped aligned inbred lines recombinant strain (STAIRS) by using exotic/unused material.

\subsection{Functional Genomics}

After developing comprehensive transcriptome assemblies (Kudapa et al. 2012) and draft genome sequence (Varshney et al. 2012), there was a need to correlate and complement the genome information to the gene expression that is modulated in a temporal and spatial manner. In this direction, a very first step has been accomplished by developing a gene expression atlas for pigeonpea (Pazhamala et al. 2017). This will be helpful in studying the genes expressed in specialized tissues/organ system in pigeonpea. Further to harness the power of natural variation at tissue level in terms of protein and metabolites, the functional genomics should move towards the development of proteome and metabolome maps in pigeonpea. The protein and metabolic differences among tissues within a plant offer another source of variation that can be harnessed in the quest to understand gene function and tackling constraint related to crop improvement.

\subsection{Next Generation Breeding}

Majority of the present breeding programs mainly rely on phenotypic selection in standard breeding schemes. Few initiatives have been taken in pigeonpea improvement programs to take genomics inputs (marker-based purity testing in hybrids and parental lines; DNA fingerprinting, etc.) for enhancing the precision. Recently, GAB for introgression of SMD and FW resistance in elite varieties has also been started at ICRISAT. The availability of draft genome, re-sequencing data, NGS, bio-informatics advances and phenotyping platforms provide opportunities to take pigeonpea improvement program a step forward to move towards the next generation breeding. Recent drop in marker genotyping cost (lower cost per data point) will make next generation breeding possible in pigeonpea. These advances will enable breeders to select the most appropriate allele combinations for a number of traits (especially for must have traits) simultaneously at early generation and facilitating their introgression from landraces or wild species accessions into elite cultivars while avoiding the risk of linkage drag.

The use of genomic selection (GS) is becoming feasible in many crops (Zhao et al. 2015). GS is expected to help to design new genotypes based on genome-wide profiling in a cost effective and relatively fast way. In particular, pigeonpea hybrid breeding program, GS 
model can be designed for developing heterotic groups of parental lines. This will improve the chances of developing high-yielding better hybrids and parental lines. Once established, GS will eliminate the need for multi-location field testing at each generation and efforts in line $\times$ tester crossing. Though we understand that genetic resources, from elite cultivars to landraces and wild species accessions, will remain the foundation of pigeonpea improvement, we expect that in near future the use of NGS or high-throughput genotyping for EGS, GS, MABC and MAS will be accelerated. In parallel, new genome engineering approaches such as genome editing will also be very useful as and when causal nucleotide affecting the trait is identified.

Acknowledgements Authors are thankful to their colleagues and collaborators like KB Saxena, CV Sameerkumar of ICRISAT and Jochen Reif of IPK-Gatersleben, Germany, for discussions and suggestions that have helped to write this chapter.

\section{References}

Abe A, Kosugi S, Yoshida K, Natsume S, Takagi H, Kanzaki H, Matsumura H, Yoshida K, Mitsuoka C, Tamiru M (2012) Genome sequencing reveals agronomically important loci in rice using MutMap. Nat Biotechnol 30:174-178

Huang BE, George AW, Forrest KL, Kilian A, Hayden MJ, Morell MK, Cavanagh CR (2012) A multiparent advanced generation inter-cross population for genetic analysis in wheat. Plant Biotechnol J 10:826-839

Kudapa H, Bharti AK, Cannon SB, Farmer AD, Mulaosmanovic B, Kramer R, Bohra A, Weeks NT, Crow JA, Tuteja R, Shah T, Dutta S, Gupta DK, Singh A, Gaikwad K, Sharma TR, May GD, Singh NK, Varshney RK (2012) A comprehensive transcriptome assembly of pigeonpea (Cajanus cajan L.) using Sanger and second-generation sequencing platforms. Mol Plant 5:1020-1028

McMullen MD, Kresovich S, Villeda HS, Bradbury P, Li H, Sun Q, Flint-Garcia S, Thornsberry J, Acharya C, Bottoms C, Brown P, Browne C, Eller M, Guill K, Harjes C, Kroon D, Lepak N, Mitchell SE, Peterson B, Pressoir G, Romero S, Rosas MO, Salvo S, Yates H, Hanson M, Jones E, Smith S, Glaubitz JC, Goodman M, Ware D, Holland JB, Buckler ES (2009) Genetic properties of the maize nested association mapping population. Science 325:737-740
Mula MG, Saxena KB (2010) Lifting the level of awareness on pigeonpea-a global perspective. International Crops Research Institute for the Semi-Arid Tropics, Patancheru

Pazhamala LT, Purohit S, Saxena RK, Garg V, Krishnamurthy L, Verdier J, Varshney RK (2017) Gene expression atlas of pigeonpea and its application to gain insights on genes associated with pollen fertility implicated in seed formation. J Exp Bot 68:2037-2054

Saxena KB (2015) From concept to field: evolution of hybrid pigeonpea technology in India. Indian J Genet 75:279-293

Saxena KB, Kumar RV, Tikle AN, Saxena MK, Gautam VS, Rao SK, Khare DK, Chauhan YS, Saxena RK, Reddy BVS, Sharma D, Reddy LJ, Green JM, Faris DG, Nene YL, Mula M, Sultana R, Srivastava RK, Gowda CLL, Sawargaonkar SL, Varshney RK (2013) ICPH 2671 - the world's first commercial food legume hybrid. Plant Breed 132:479-485

Semagn K, Bjornstad A, Xu Y (2010) The genetic dissection of quantitative traits in crops. Electron $\mathbf{J}$ Biotechnol 13: article 14 13(5): 16-17

Sharma S, Upadhyaya HD, Varshney RK, Gowda CLL (2013) Pre-breeding for diversification of primary gene pool and genetic enhancement of grain legumes. Front Plant Sci 4:309. doi:10.3389/fpls.2013.00309

Singh NB, Singh IP, Singh BB (2005) Pigeonpea breeding. Advances in pigeonpea research. Indian Institute of Pulses Research, Kanpur, India, pp 67-95

Singh VK, Khan AW, Saxena RK, Kumar V, Kale SM, Sinha P, Chitikineni A, Pazhamala LT, Garg V, Sharma M, Sameerkumar CV, Parupalli S, Suryanarayana V, Patil S, Muniswamy S, Ghanta A, Yamini KN, Dharmaraj PS, Varshney RK (2015) Next generation sequencing for identification of candidate genes for fusarium wilt and sterility mosaic disease in pigeonpea (Cajanus cajan). Plant Biotechnol J. doi:10.1111/pbi.12470

Singh VK, Khan AW, Saxena RK, Sinha P, Kale SM, Parupalli S, Kumar V, Chitikineni A, Vechalapu S, Sameer Kumar CV, Sharma M, Ghanat A, Yamini KN, Muniswamy S, Varshney RK (2017) Indel-seq: a fast-forward genetics approach for identification of trait-associated putative candidate genomic regions and its application in pigeonpea (Cajanus cajan). Plant Biotechnol J. doi:10.1111/pbi.12685

Upadhyaya HD, Gowda CLL, Buhariwalla HK, Crouch JH (2006) Efficient use of crop germplasm resources: identifying useful germplasm for crop improvement through core and mini-core collections and molecular marker approaches. Plant Genet Resour 4:25-35

Varshney RK, Chen W, Li Y, Bharti AK, Saxena RK, Schlueter JA, Donoghue MTA, Azam S, Fan G, Whaley AM, Farmer AD, Sheridan J, Iwata A, Tuteja R, Penmetsa RV, Wu W, Upadhyaya HD, Yang SP, Shah T, Saxena KB, Michael T, McCombie WR, Yang B, Zhang G, Yang H, Wang J, Spillane C, Cook DR, May GD, Xu X, Jackson SA (2012) Draft genome sequence of pigeonpea (Cajanus 
cajan), an orphan legume crop of resource-poor farmers. Nat Biotechnol 30:83-89

Varshney RK, Saxena RK, Upadhyaya HD, Khan AW, Yu Y, Kim C, Rathore A, Kim D, Kim J, An S, Kumar V, Anuradha G, Yamini KN, Zhang W, Muniswamy S, Kim JS, Penmetsa RV, von Wettberg E, Datta SK (2017) Whole-genome resequencing of 292 pigeonpea accessions identifies genomic regions associated with domestication and agronomic traits. Nat Genet 49:1082-1088

Zhao Y, Li Z, Liu G, Jiang Y, Maurer HP, Würschum T, Mock HP, Matros A, Ebmeyer E, Schachschneider R, Kazman E (2015) Genome-based establishment of a high-yielding heterotic pattern for hybrid wheat breeding. Proc Nat Acad Sci 112:1562415629 